\title{
Identification by array comparative genomic hybridization of a new amplicon on chromosome $17 q$ highly recurrent in BRCA1 mutated triple negative breast cancer
}

Sébastien Toffoli ${ }^{1 *+}$, Isabelle Bar ${ }^{1+}$, Fadi Abdel-Sater ${ }^{2}$, Paul Delrée ${ }^{3}$, Pascale Hilbert ${ }^{4}$, Frédéric Cavallin ${ }^{4}$, Fabrice Moreau ${ }^{5}$, Wim Van Criekinge ${ }^{5}$, Magali Lacroix-Triki ${ }^{6}$, Mario Campone ${ }^{7}$, Anne-Laure Martin ${ }^{8}$, Henri Roché ${ }^{9}$, Jean-Pascal Machiels ${ }^{10}$, Javier Carrasco ${ }^{11}$ and Jean-Luc Canon ${ }^{11}$

\begin{abstract}
Introduction: Triple Negative Breast Cancers (TNBC) represent about 12\% to 20\% of all breast cancers (BC) and have a worse outcome compared to other BC subtypes. TNBC often show a deficiency in DNA double-strand break repair mechanisms. This is generally related to the inactivation of a repair enzymatic complex involving BRCA1 caused either by genetic mutations, epigenetic modifications or by post-transcriptional regulations.

The identification of new molecular biomarkers that would allow the rapid identification of BC presenting a BRCA1 deficiency could be useful to select patients who could benefit from PARP inhibitors, alkylating agents or platinum-based chemotherapy.
\end{abstract}

Methods: Genomic DNA from 131 formalin-fixed paraffin-embedded (FFPE) tumors (luminal A and B, HER2+ and triple negative $\mathrm{BC}$ ) with known BRCA1 mutation status or unscreened for BRCA1 mutation were analysed by array Comparative Genomic Hybridization (array CGH). One highly significant and recurrent gain in the 17q25.3 genomic region was analysed by fluorescent in situ hybridization (FISH). Expression of the genes of the 17q25.3 amplicon was studied using customized Taqman low density arrays and single Taqman assays (Applied Biosystems).

Results: We identified by array CGH and confirmed by FISH a gain in the $17 q 25.3$ genomic region in $90 \%$ of the BRCA1 mutated tumors. This chromosomal gain was present in only $28.6 \%$ of the BRCA1 non-mutated TNBC, $26.7 \%$ of the unscreened TNBC, $13.6 \%$ of the luminal B, 19.0\% of the HER2+ and 0\% of the luminal A breast cancers. The 17q25.3 gain was also detected in $50 \%$ of the TNBC with BRCA1 promoter methylation. Interestingly, BRCA1 promoter methylation was never detected in BRCA1 mutated BC. Gene expression analyses of the 17q25.3 sub-region showed a significant over-expression of 17 genes in BRCA1 mutated TNBC $(n=15)$ as compared to the BRCA1 non mutated TNBC $(n=13)$.

Conclusions: In this study, we have identified by array CGH and confirmed by FISH a recurrent gain in 17q25.3 significantly associated to BRCA1 mutated TNBC. Up-regulated genes in the 17q25.3 amplicon might represent potential therapeutic targets and warrant further investigation.

\footnotetext{
* Correspondence: sebastien.toffoli@ipg.be

${ }^{\dagger}$ Equal contributors

'Laboratory of Translational Oncology, Institute of Pathology and Genetics/

Grand Hôpital de Charleroi, Avenue Georges Lemaitre 25, Gosselies 6041,

Belgium

Full list of author information is available at the end of the article
}

\section{Biomed Central}

(c) 2014 Toffoli et al.; licensee BioMed Central Ltd. This is an Open Access article distributed under the terms of the Creative Commons Attribution License (http://creativecommons.org/licenses/by/2.0), which permits unrestricted use, distribution, and reproduction in any medium, provided the original work is properly credited. The Creative Commons Public Domain Dedication waiver (http://creativecommons.org/publicdomain/zero/1.0/) applies to the data made available in this article, unless otherwise stated. 


\section{Introduction}

Breast cancer $(\mathrm{BC})$ is the most frequent female cancer, and is a complex and heterogeneous disease. Molecular analyses based on cDNA microarrays have revealed distinctive subtypes of $\mathrm{BC}$, each characterized by a specific gene expression profile [1-3]. These subtypes include luminal A and B (positive for estrogen receptor (ER) and/or progesterone receptor (PR)), human epidermal growth factor 2-positive (HER2+) (high expression of the HER2 oncogene) and basal-like breast cancer (BLBC, expressing genes specifically of the basal cells of the normal breast) $[4,5]$. The majority of BLBC are triple-negative (TN). TN breast cancer (TNBC) (that is, ER-negative, PR-negative, HER2-negative $\mathrm{BC}$ ) accounts for about 12 to $20 \%$ of all BC [6]. BC subtypes are associated with different clinical outcomes, with the best prognosis for luminal A cancers and the worst for TN tumors. TNBC tumors are statistically larger in size, are of higher grade, and are biologically more aggressive compared to other cancer subtypes, with fewer than $30 \%$ of women with metastatic TNBC alive 5 years after diagnosis. These tumors constitute an important clinical challenge, as they do not respond to endocrine treatment or any other targeted therapies related to the absence of well-defined molecular targets.

One of the first molecular insights into TNBC came from the observation that $\mathrm{BC}$ from patients with $B R C A 1$ germline mutations, and from TNBC/BLBC patients, share a similar phenotype by immunohistochemistry or gene expression microarray [7]. Indeed, up to $90 \%$ of tumors with BRCA1 mutation are triple-negative and about 10 to $20 \%$ of TNBC harbor a germline mutation in BRCA1 [8,9].

BRCA1 functions as a tumor suppressor protein that preserves genome integrity. Cells with homozygous BRCA1 deficiency cannot repair DNA double-strand breaks, which results in a significant increase in genomic alterations and instability, finally leading to the development of tumors [10]. Several studies have shown that BRCA1-mutated tumors are sensitive to chemotherapy with DNA crosslinking agents such as platinum salts and alkylating agents, which lead to the formation of double-strand DNA breaks that cannot be repaired [11-13]. Another promising but still to be confirmed approach in the treatment of TNBC relies on the putative sensitivity of these tumors to poly ADP-ribose polymerase (PARP) inhibitors [14].

It is critical to identify tumors deficient in BRCA1 to select patients who could benefit from these selective treatments. The accumulation of gains and/or losses in the genome of $B R C A 1$-mutated $\mathrm{BC}$ can generate a pattern of chromosomal aberrations that could constitute a molecular signature, and it has been shown that BRCA1-mutated tumors develop a particular comparative genomic hybridization (CGH) profile [13,15-18]. In this study, we report the analysis by array $\mathrm{CGH}$ and fluorescent in situ hybridization (FISH) of 44 TNBC of known BRCA1 status and well-defined histopathological features, and the identification of a recurrent region specifically gained in BRCA1-mutated TNBC. We have combined these results with gene expression data and highlighted the over-expression of genes that may prove to be important for TNBC development and progression.

\section{Methods}

\section{Tumor samples}

Formalin-fixed paraffin-embedded (FFPE) tumors were selected from the biobank of the Institute of Pathology and Genetics (IPG, Gosselies, Belgium). The BRCA1 status was known for 53 patients screened in the context of a familial history of breast cancer or young age of diagnosis (23 with mutated TNBC, 9 with mutated non TNBC (7 with luminal A and 2 with HER2+ tumors) and 21 nonmutated TNBC). All the BRCA1 wild-type tumors have a non-mutated $B R C A 2$ gene. We also analyzed $78 \mathrm{BC}$ that were not screened for $B R C A 1$ mutation: 20 luminal $\mathrm{A} B C$, 22 luminal B BC, 21 HER2+ BC and 15 TNBC.

In our study, luminal A was defined as $\mathrm{ER}+$ or $\mathrm{PR}+$, HER2-, and low Ki67 index ( $<14 \%)$; luminal B was defined as ER+ or PR+ and HER2- with high Ki67 index ( $\geq 30 \%)$; HER2+ was defined as ER+ or ER-, PR+ or PRand HER2+ amplified. The TN group was defined as ER-, PR-, and HER2-. The cutoff for ER or PR to define a sample as negative was $3 \%$.

These tumors were further characterized for cytokeratin (CK) 5/6, CK14, p63 and epidermal growth factor receptor (EGFR) expression by immunohistochemical (IHC) staining on tissue microarray (TMA). TMA were constructed as follows: H\&E slides were reviewed by a pathologist to select representative infiltrating tumor area. Four tissue cores ( $0.6 \mu \mathrm{m}$ diameter each, 3 tumoral and 1 normal control) were sampled from each block to account for tumor heterogeneity and inserted in a new receiver block. Staining IHC was performed in an Autostainer Plus (DAKO, Glostrup, Denmark) with the EnVisionFlex (DAKO, Glostrup, Denmark).

$B R C A 1$ and BRCA2 status of patients was determined by geneticists with the patient agreement and according to the ethical rules in the context of a familial cancer investigation. All experiments involving human tissues were conducted with the permission of the ethics committee of the Grand Hôpital de Charleroi (GHdC, Charleroi, Belgium). Patients' characteristics are summarized in Table 1.

\section{Array comparative genomic hybridization (array CGH)}

The invasive tumor component was selected by a pathologist on H\&E sections of the FFPE blocks. Four to six $10-\mu \mathrm{m}$ FFPE sections per tumor were used for CGH analyses and the infiltrating tumor region was macrodissected. Normal matched tissues were also analyzed as control $(n=4)$. DNA extraction, sample preparation and hybridization were carried out according to the manufacturer's protocols for FFPE samples (Number G4410-90020, Protocol version 3.3, August 2011, Agilent Technologies, 
Table 1 Patient and tumor characteristics

\begin{tabular}{|c|c|c|c|c|c|c|c|c|}
\hline \multirow[b]{3}{*}{ Clinical characteristics } & \multicolumn{3}{|l|}{ BRCA1 } & \multirow{3}{*}{$\begin{array}{l}\text { BRCA1 } \\
\text { Non mutated } \\
\text { TN }\end{array}$} & \multicolumn{4}{|l|}{ BRCA1 } \\
\hline & \multicolumn{3}{|l|}{ Mutated } & & \multicolumn{4}{|c|}{ Unscreened } \\
\hline & TN & Lum A & HER2+ & & TN & $\operatorname{Lum} A$ & Lum B & HER2+ \\
\hline Tumors analyzed, $\mathrm{n}$ & 23 & 7 & 2 & 21 & 15 & 20 & 22 & 21 \\
\hline Age, years, mean & 44 & 44 & 48 & 50 & 59 & 63 & 59 & 59 \\
\hline (range) & (28 to 60$)$ & (29 to 71$)$ & (42 to 54 ) & (28 to 72 ) & (31 to 83 ) & (43 to 86 ) & (37 to 85 ) & (34 to 84 ) \\
\hline \multicolumn{9}{|l|}{ Histology, n (\%) } \\
\hline \multirow[t]{2}{*}{ Ductal } & 20 & 7 & 2 & 19 & 14 & 18 & 21 & 19 \\
\hline & $(87 \%)$ & $(100 \%)$ & $(100 \%)$ & $(90 \%)$ & (93\%) & $(90 \%)$ & $(69 \%)$ & $(90 \%)$ \\
\hline \multirow[t]{2}{*}{ Lobular } & 1 & 2 & 0 & 1 & 0 & 2 & 1 & 2 \\
\hline & $(4 \%)$ & $(29 \%)$ & $(0 \%)$ & $(5 \%)$ & $(0 \%)$ & $(10 \%)$ & $(5 \%)$ & $(10 \%)$ \\
\hline \multirow[t]{2}{*}{ Metaplastic } & 0 & 0 & 0 & 1 & 0 & 0 & 0 & 0 \\
\hline & $(0 \%)$ & $(0 \%)$ & $(0 \%)$ & $(5 \%)$ & $(0 \%)$ & $(0 \%)$ & $(0 \%)$ & $(0 \%)$ \\
\hline \multirow[t]{2}{*}{ Medullary } & 2 & 0 & 0 & 0 & 0 & 0 & 0 & 0 \\
\hline & $(8.7 \%)$ & $(0 \%)$ & $(0 \%)$ & $(0 \%)$ & $(0 \%)$ & $(0 \%)$ & $(0 \%)$ & $(0 \%)$ \\
\hline \multirow[t]{2}{*}{ Grade I } & 0 & 0 & 0 & 1 & 0 & 12 & 1 & 3 \\
\hline & $(0 \%)$ & $(0 \%)$ & $(0 \%)$ & $(5 \%)$ & $(0 \%)$ & $(60 \%)$ & $(5 \%)$ & $(14 \%)$ \\
\hline \multirow[t]{2}{*}{ Grade II } & 0 & 3 & 0 & 3 & 3 & 7 & 9 & 9 \\
\hline & $(0 \%)$ & $(43 \%)$ & $(0 \%)$ & $(14 \%)$ & $(20 \%)$ & $(35 \%)$ & $(41 \%)$ & $(43 \%)$ \\
\hline \multirow[t]{2}{*}{ Grade III } & 23 & 4 & 2 & 17 & 12 & 1 & 12 & 9 \\
\hline & $(100 \%)$ & $(57 \%)$ & $(100 \%)$ & $(81 \%)$ & $(80 \%)$ & $(5 \%)$ & $(55 \%)$ & $(43 \%)$ \\
\hline \multicolumn{9}{|l|}{ Immunohistochemistry, $\mathrm{n}$ (\%) } \\
\hline \multirow[t]{2}{*}{ ER-positive, n (\%) } & 0 & 7 & 0 & 0 & 0 & 20 & 22 & 12 \\
\hline & $(0 \%)$ & $(100 \%)$ & $(0 \%)$ & $(0 \%)$ & $(0 \%)$ & $(100 \%)$ & $(100 \%)$ & $(57 \%)$ \\
\hline \multirow[t]{2}{*}{ PR-positive, n (\% } & 0 & 5 & 0 & 0 & 0 & 20 & 22 & 12 \\
\hline & $(0 \%)$ & $(71 \%)$ & $(0 \%)$ & $(0 \%)$ & $(0 \%)$ & $(100 \%)$ & $(100 \%)$ & $(57 \%)$ \\
\hline \multirow[t]{2}{*}{ HER2-positive, n (\%) } & 0 & 0 & 2 & 0 & 0 & 0 & 0 & 21 \\
\hline & $(0 \%)$ & $(0 \%)$ & $(100 \%)$ & $(0 \%)$ & $(0 \%)$ & $(0 \%)$ & $(0 \%)$ & $(100 \%)$ \\
\hline KI67, mean, \% & 42 & 7 & 47 & 35 & 48 & 7 & 44 & 34 \\
\hline \multirow[t]{2}{*}{ P63- or EGFR- or CK14- or CK5/6-positive, n (\%) } & 11 & 1 & 1 & 7 & 9 & 0 & 1 & 3 \\
\hline & $(48 \%)$ & $(14 \%)$ & $(50 \%)$ & $(33 \%)$ & $(60 \%)$ & $(0 \%)$ & $(5 \%)$ & $(14 \%)$ \\
\hline \multicolumn{9}{|l|}{ Array CGH } \\
\hline \multirow[t]{2}{*}{ Gain in 17q25.3, n (\%) } & 20 & 7 & 2 & 6 & 4 & 0 & 3 & 4 \\
\hline & $(87 \%)$ & $(100 \%)$ & $(100 \%)$ & $(29 \%)$ & $(27 \%)$ & $(0 \%)$ & $(14 \%)$ & $(19 \%)$ \\
\hline
\end{tabular}

TN, triple-negative; Lum, luminal; HER2+, human epidermal growth factor 2-positive; ER, estrogen receptor; PR, progesterone receptor; EGFR, epidermal growth factor receptor; CK, cytokeratin; ACGH, array comparative genomic hybridization.

Santa Clara, California, USA). A pool of seven different genomic DNA (gDNA) from seven healthy female donors, randomly chosen, was used as reference genome. CGHarray was performed using $8 \times 60 \mathrm{~K}$ SurePrint G3 Human CGH Microarrays (Number G4450A, Agilent Technologies, Santa Clara, California, USA), which were scanned with an Agilent type C scanner (Agilent Technologies, Santa Clara, California, USA). Feature extraction software (version 10.7.3.1) with an hg19 annotated design file (021924_D_F_20111015) and a modified Agilent-provided extraction protocol (CGH_107_Sep09) (Agilent Technologies, Santa Clara, California, USA) were used to extract raw data from tiff files obtained after scanning. The arraybased CGH data were analyzed with the Agilent Genomic Workbench 7.0 (Agilent Technologies, Santa Clara, California, USA). The $Z$-score algorithm was used with a threshold of 0.2 and a $2-\mathrm{Mb}$ sliding window to detect significantly aberrant genomic regions (QQ-plots on the $P$-value from the enrichment analysis confirmed that the chosen threshold did not over-call some aberrations). Our copy number 
variation data were compared to the Database of Genomic Variants [19] to exclude genomic variants. Array CGH data are available through GEO [GSE54140].

\section{Enrichment analysis}

Genomic intervals which have a significant overabundance of gains or losses in a given genomic region were identified with the hypergeometric tail algorithm available in Genomic Workbench 7.0 (Agilent Technologies, Santa Clara, California, USA). In Genomic Workbench 7.0, the genomic intervals are constructed from the data obtained with the aberration detection algorithm ( $Z$-score algorithm) using a $2-\mathrm{Mb}$ sliding window with a threshold at 0.2 . The genomics intervals calculated by the $Z$-score algorithm are then used in the enrichment analysis. $P$-values of significant chromosomal regions $(P \leq 0.01)$ were $-\log$ 10 transformed and plotted according to the genomic position.

\section{Fluorescent in situ hybridization}

FISH was performed using the Histology FISH Accessory kit (DAKO, Glostrup, Denmark) on 5- $\mu \mathrm{m}$ sections from FFPE samples, as recommended by the manufacturer. The probes consisted of a chromosome-17 centromeric probe (CEP17 Spectrum Green ${ }^{\mathrm{mm}}$ probe, Vysis, Abbott Molecular, Des Plaines, Illinois, USA) and an in-house generated bacterial artificial chromosome (BAC) probe located in the amplified region of chromosome 17 (clone RP11-1055B8). The BAC probe was labeled with SpectrumOrange ${ }^{\text {tu }}$ using a nick translation kit (Abbott Molecular, Des Plaines, Illinois, USA) and the specificity of the BAC probe was verified on leucocytes by metaphase FISH.

Images were collected with the BioView Duet ${ }^{\mathrm{mix}}$ System (BioView Ltd, Rehovot, Israel). Signals from both probes were scored in about 100 non-overlapping nuclei with malignant morphology in the infiltrating tumor zone (as selected by the pathologist). Adjacent fibroblasts or lymphocytes and residual normal breast tissues were used as internal control. For each tumor, the mean number of signals corresponding to the RP11-1055B8 probe was calculated. The ratio between the RP11-1055B8 probe and the centromeric probe was also evaluated for individual nuclei and the percentage of the nuclei with a ratio $\geq 3$ was calculated for each TNBC. FISH slides were analyzed blinded to the CGH results.

\section{RNA isolation and CDNA synthesis}

The invasive tumor zone, selected by the pathologist on $H \& E$ section, was macrodissected from unstained FFPE sections. Two to four $20-\mu \mathrm{m}$ sections per tumor were used for the RNA extraction. Isolation of total ribonucleic acids was performed using the RecoverAll Total Nucleic Acid Isolation kit (Ambion, Life Technologies, Carlsbad, California, USA) according to the manufacturer's protocol for FFPE samples. Extracted RNA was reverse transcribed into cDNA using the High Capacity cDNA Reverse Transcription Kit (Applied Biosystems, Life Technologies, Carlsbad, California, USA) according to the manufacturer's recommendations.

\section{Taqman low-density arrays}

Customised Taqman low-density arrays from Applied Biosystems (Life Technologies, Carlsbad, California, USA) were used to study the expression of 65 genes belonging to the $17 \mathrm{q} 25.3$ chromosomal region, as well as 18 putative housekeeping genes. For each tumor, one microgram of cDNA was loaded into two channels (500 ng cDNA/channel) of a microfluidic card, which was run on an Applied Biosystems 7900 HT Real-Time PCR System (Life Technologies, Carlsbad, California, USA) according to the manufacturer's recommendation (Protocol number 4400263 Rev. B). Best housekeeping genes (POLR2A, RPS11, GUSB, $R P L 37 A, A C T B)$ for data normalization were chosen according to their stability score calculated by the Expression Suite 1.0.1 software (Life Technologies, Carlsbad, California, USA). Transcript levels were expressed as $2^{-\Delta \mathrm{Ct}}$, where $\Delta \mathrm{Ct}$ (cycle threshold) $=\mathrm{CT}_{\text {gene }}-\mathrm{CT}_{\text {mean }}$ of five housekeeping genes.

\section{qPCR validation}

Individual Taqman assays were performed in MicroAmp ${ }^{\circ}$ Optical 96-Well Reaction Plates (Applied Biosystems, Life Technologies, Carlsbad, California, USA) according to the provided protocol (number 4333458 Rev. N 11/2010, Applied Biosystems, Life Technologies, Carlsbad, California, USA). Ten nanograms of cDNA were used in each qPCR reaction run on a $7900 \mathrm{HT}$ Real-Time PCR System (Applied Biosystems, Life Technologies, Carlsbad, California, USA). Based on the Taqman low-density array analyses previously carried out, $A C T B, G U S B, P O L R 2 A, R P L 37 A$ and RPS11 were chosen as housekeeping genes. Transcript levels were expressed as $2^{-\Delta \mathrm{Ct}}$, where $\Delta \mathrm{Ct}=\mathrm{CT}_{\text {gene }}-\mathrm{CT}_{\text {mean }}$ of five housekeeping genes.

\section{Methylation analysis}

BRCA1 promoter methylation was determined by realtime quantitative-methylation-specific PCR (QMSP) $[20,21]$. The BRCA1 amplicon used is significantly overlapping with the CpGs as previously reported by Veeck et al. [21]. Methylation ratios (× 1000) were determined relative to the $A C T B$ reference gene. A standard curve of a serial dilution of a dual plasmid containing both BRCA1 and $A C T B$ was used for absolute quantification. 


\section{Statistical analysis}

FISH results were analyzed using the Mann-WhitneyWilcoxon test. Statistical analysis of the Taqman lowdensity array data and the individual Taqman qPCR data was performed by Student's $t$-test using Graphpad Prism software (GraphPad Software, La Jolla, California, USA) ( $P<0.05$; ${ }^{* *} P<0.01$; $\left.{ }^{* * *} P<0.001\right)$. The sensitivity was calculated as the proportion of BRCA1-mutated BC with a gain in 17q25.3 (true positives/true positives + false negative). The specificity was calculated as the proportion of $\mathrm{BC}$ without BRCA1 mutation without a gain in 17q25.3 (true negative/true negative + false positive).

\section{Results}

Comparative analysis of $B R C A 1$-mutated and non-mutated TNBC array CGH profiles

As described in the literature, accumulation of gains and/or losses in the genome can generate a pattern of chromosomal aberrations, which could constitute a molecular signature [13,15-18]. On the basis of these elements, we investigated whether such patterns of chromosomal aberrations could be observed in BRCA1 mutated TNBC as compared to non mutated TNBC. Genomic DNA of 23 BRCA1-mutated and 21 non-mutated TNBC was studied by array $\mathrm{CGH}$. For each tumor, all chromosome aberrations were plotted according to their position in the genome in order to generate an aberration profile. Individual profiles belonging to the same group of tumors (BRCA1-mutated or non-mutated) were summed to produce a global profile (Figure 1A and B). The general distribution of the genomic aberrations was relatively similar between the two tumor groups and showed a high proportion of gains and losses in both BRCA1-mutated and non-mutated TNBC (mutated TNBC: mean 102 aberrations per genome, range 18 to 211 ; non-mutated TNBC: mean 134 aberrations per genome, range 14 to 246). In order to pinpoint the significant

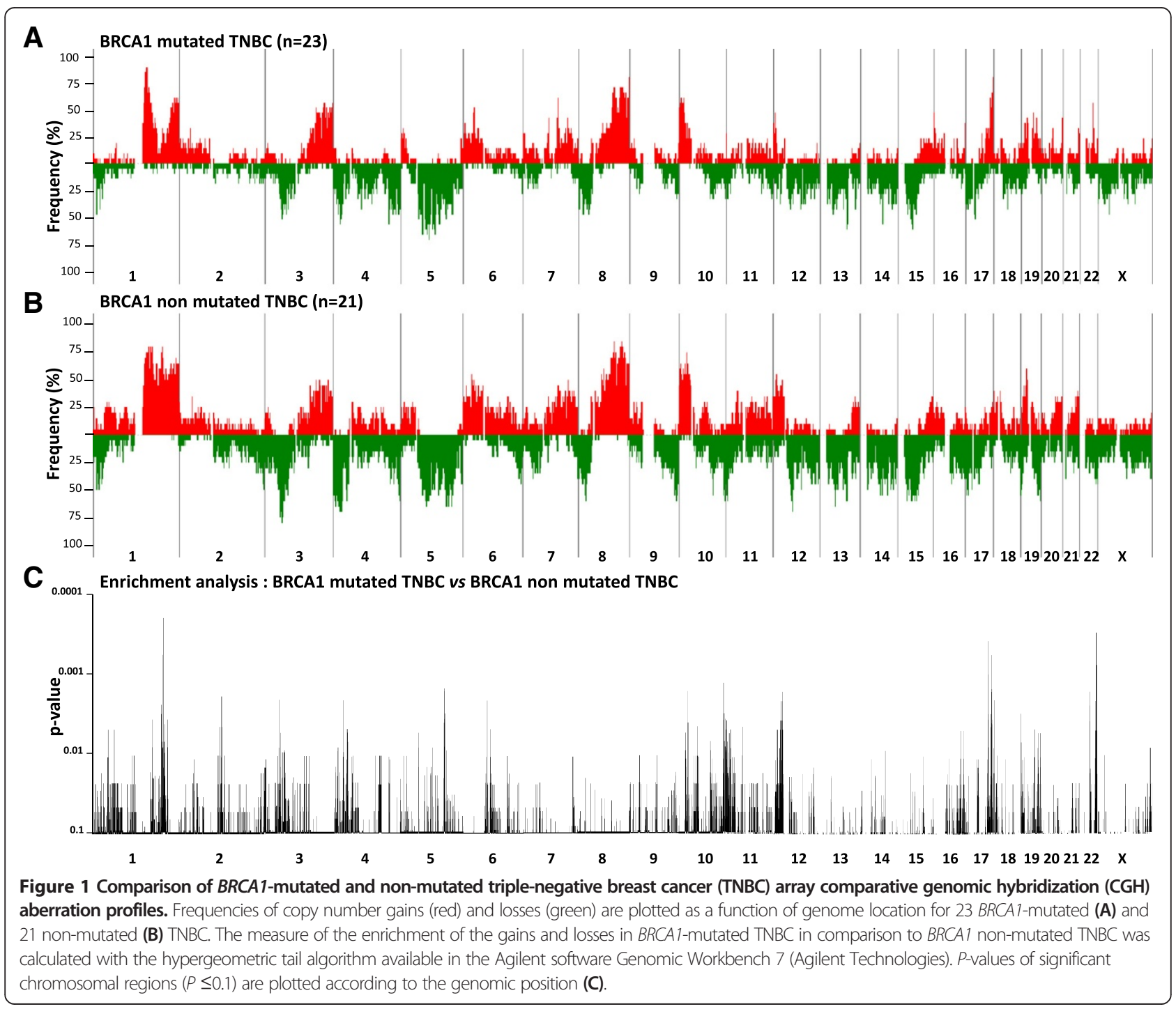


differences between the two profiles, data were analyzed with the software Genomic Workbench 7.0 in combination with the hypergeometric tail algorithm (Figure 1C). We considered aberrations with a difference in frequency of at least $20 \%$ between the two groups, and with a $P$-value below 0.05 .

The most frequent discriminating genomic alterations in the BRCA1-mutated group as compared to the nonmutated group were gains in $7 \mathrm{p} 22.1,8 \mathrm{q} 24.3,11 \mathrm{p} 15.5,15 \mathrm{q}$ 22.31, 15q24.1-2, 16p24.3, 17q24.1, 17q24.3, 17q25.1, 17q 25.3, 19q13.33, 22q12.3, 22q13.1, and losses in 5q14.3-21.2, 5q23.1, 11q24.3, 12q21.33, 18q12.1, 18q12.3, 19q13.2-3 (Table 2, and Table S1 in Additional file 1).

Several other significant gains and losses were detected in the non-mutated group, but these corresponded to regions that were preserved in the BRCA1-mutated tumors, like the chromosomal 1q31.3 region (Table S2 in Additional file 2). Amongst all the relevant aberrations, the most consistent gain in BRCA1-mutated TNBC was a highly significant $(P=0.0002)$ and recurrent gain of $2.4 \mathrm{Mb}$ located between the position 78644018 and 81029941 on the chromosome 17 (17q25.3 (Human Genome built
37)). In the Database of Genomic Variant, most of the $\mathrm{CNV}$ in that region are losses, and we did not detect the $17 \mathrm{q} 25.3$ gain in normal tissue adjacent to positive tumor tissue, suggesting that this gain is not a copy number polymorphism. The gain in the $17 \mathrm{q} 25.3$ region was detected in $86.96 \%$ of BRCA1-mutated TNBC (20/ 23 ; sensitivity of $87 \%$ ), and was only detected in $28.57 \%$ of non-mutated TNBC (6/21, specificity of $71 \%$ ) (Figure $2 \mathrm{~A}$ and B).

Other gains were also highly significant, but were less frequent in the mutated samples. For example, the 22q13.1 gain was only found in 13/23 (51\%) of the TN mutated samples and was also found in 6/21 (20\%) of the nonmutated TN samples.

Incorporating other significant regions (145 aberrations, Additional file 3: Table S3) into a classifier did not improve our sensitivity (21/23 cases detected, sensitivity of $91 \%$ ), but did improve the specificity to $100 \%$ (see supplementary methods and results in Additional file 4). In this classifier, the chromosome 17 region 7826081081029941 was also identified as the most important variable in discriminating between mutated and non-

Table 2 Main chromosomal aberrations detected in BRCA1-mutated TNBC

\begin{tabular}{|c|c|c|c|c|c|}
\hline \multirow[b]{2}{*}{ Chromosomes } & \multirow[b]{2}{*}{ Cytobandes } & \multicolumn{2}{|c|}{ BRCA1-mutated } & \multicolumn{2}{|c|}{ BRCA1-non-mutated } \\
\hline & & Gains, \% & Losses, \% & Gains, \% & Losses, \% \\
\hline chr 5 & $\mathrm{q} 14.3-\mathrm{q} 21.2$ & 0.36 & 43.48 & 0.00 & 15.08 \\
\hline chr 5 & q23.1 & 0.00 & 39.13 & 0.00 & 14.29 \\
\hline chr7 & p22.1 & 26.09 & 13.04 & 4.76 & 11.91 \\
\hline chr8 & q24.3 & 82.61 & 4.35 & 57.14 & 9.52 \\
\hline chr11 & p15.5 & 26.09 & 8.70 & 4.76 & 47.62 \\
\hline chr11 & q24.3 & 4.35 & 26.09 & 19.05 & 4.76 \\
\hline chr12 & p12.1 & 8.70 & 34.78 & 47.62 & 14.29 \\
\hline chr12 & $\mathrm{q} 21.33$ & 0.00 & 39.13 & 4.76 & 9.52 \\
\hline chr15 & $\mathrm{q} 22.31$ & 26.09 & 13.04 & 4.76 & 14.29 \\
\hline chr15 & $q 24.1-q 24.2$ & 23.92 & 16.67 & 2.38 & 33.33 \\
\hline chr16 & q24.3 & 32.29 & 13.04 & 9.52 & 41.50 \\
\hline chr17 & q24.1 & 39.13 & 4.35 & 14.29 & 4.76 \\
\hline chr17 & q24.3 & 35.87 & 0.00 & 9.52 & 4.76 \\
\hline chr17 & $q 25.1-q 25.3$ & 58.95 & 3.59 & 25.12 & 21.63 \\
\hline chr18 & q12.1 & 10.87 & 28.26 & 15.48 & 4.76 \\
\hline chr18 & q12.3 & 0.00 & 42.03 & 0.00 & 14.29 \\
\hline chr19 & q13.2 & 21.74 & 4.35 & 0.00 & 42.86 \\
\hline chr19 & q13.33 & 21.74 & 8.70 & 0.00 & 42.86 \\
\hline chr19 & q13.42 & 26.09 & 17.39 & 4.76 & 38.10 \\
\hline chr22 & q12.3 & 49.28 & 11.59 & 11.91 & 30.16 \\
\hline chr22 & q13.1 & 50.79 & 11.07 & 19.70 & 33.33 \\
\hline
\end{tabular}

Significant aberrations ( $P$-value $\leq 0.05$ ) with a variation of gains or losses between BRCA1-mutated and non-mutated triple-negative breast cancer (TBNC) of at least $20 \%$ are indicated. 


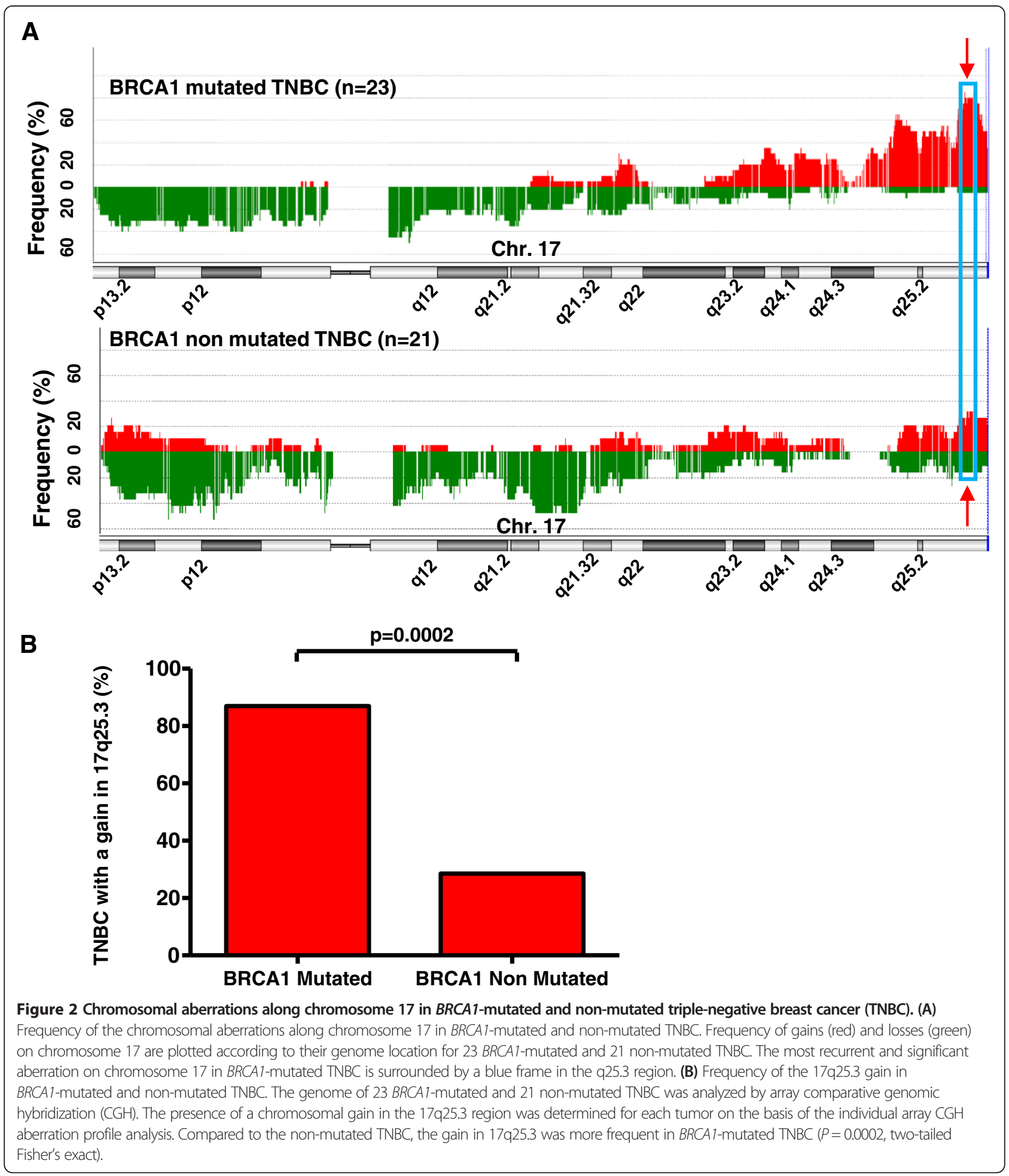

mutated samples. As the $17 \mathrm{q} 25.3$ gain was the most frequent gain in our BRCA1-mutated population, and has not yet been described in the context of BRCA1 mutation, we have decided to characterize it further.
Validation of the 17q25.3 gain by fluorescent in situ hybridization

In order to validate the $17 \mathrm{q} 25.3$ gain detected by array $\mathrm{CGH}, \mathrm{FISH}$ assays were carried out on all TNBC using a 
17q25.3-specific BAC probe (BAC RP11-1055B8) together with a chromosome 17 centromeric control probe (cen 17 probe). In the FISH experiment illustrated in Figure 3 , up to 10 copies of the $17 \mathrm{q} 25.3$ region were counted in the BRCA1-mutated tumor cells, whereas the signal was limited to two copies per nucleus in the nonmutated TNBC.

In all the cases where a gain in $17 q 25.3$ was detected by CGH (20 BRCA1-mutated cases and 6 non-mutated cases), the gain was also detected by FISH and we observed an average of 3.5 copies of the $17 \mathrm{q} 25.3$ region and a maximum of 12 copies (median (IQR) 3.5 (2.7 to $4.2), \mathrm{n}=20$ for the mutated samples, and 3.6 (2.9 to 4.6), $\mathrm{n}=6$ for the non-mutated cases). In the samples where a gain was not detected by $\mathrm{CGH}$, the mean copy number of the $17 \mathrm{q} 25.3$ region was $2.0(1.8(1.8$ to 2.7$), \mathrm{n}=3)$ for the mutated samples and 2.1 ((1.7 to 2.6), $\mathrm{n}=15$ for the non mutated cases) (Table 3). The difference between the groups with or without a gain was highly significant $(P<0.0001$, Mann-Whitney test). These results confirm the data obtained by array $\mathrm{CGH}$ analysis.

We also evaluated the $17 \mathrm{q} 25.3 /$ cen 17 ratio in individual nuclei of the BRCA1-mutated or non-mutated group. The percentage of nuclei with a $17 q 25.3 /$ cen 17 ratio above 3\% was higher in the CGH-positive cases (median (IQR) 20.6 (11.5 to 35.4), 20 mutated samples and 6 non-mutated samples), compared to $\mathrm{CGH}$-negative cases (median (IQR) 0.0 to 3.8), 15 non-mutated samples and 3 mutated samples) (Table 3). In summary, the CGH results were confirmed by FISH and these analyses confirmed the significant recurrence of the $17 q 25.3$ gain in BRCA1-mutated TNBC.

\section{Study of the 17q25.3 gain in different subgroups of breast cancers}

According to our $\mathrm{CGH}$ analyses, the $17 \mathrm{q} 25.3$ gain is highly recurrent in TNBC with $B R C A 1$ mutation. We then investigated if the 17q25.3 gain could be detected in other subgroups of breast cancer. The presence of the 17q25.3 gain was assessed in 9 BRCA1-mutated non-TNBC (7 luminal $A$ and 2 HER2+) and in a cohort of 78 BC unscreened for BRCA1 mutation (20 luminal A, 22 luminal B, 21 HER2+ and 15 TNBC) (Table 1). The presence of the gain was determined on the basis of the individual array $\mathrm{CGH}$ profiles generated for each tumor. In the BRCA1 unscreened population, the $17 \mathrm{q} 25.3$ gain was only detected in 3/22 luminal B (13.6\%), 4/21 HER2+ (19\%) and $4 / 15$ TNBC (26.7\%). No 17q25.3 gain was observed in the luminal A subgroup. The gain was detected in all the BRCA1-mutated non-TNBC (9/9) (100\%) (Figure 4).

In summary, the prevalence of $17 q 25.3$ gain did not exceed $17.2 \%$ in unscreened and non-mutated breast cancers (17/99), while the gain was observed in more than $90 \%$ of the BRCA1-mutated tumors (29/32). To further validate our results on an independent cohort, we analyzed the Breast Invasive Carcinoma cohort from TCGA [22] (Additional file 4). This cohort contains mutation data for 507 samples, copy number data for 778 samples, expression data for 526 samples and methylation data for 311 samples. BC cases (77 TN, 201 LumA, 101 LumB and 38 HER2+) were selected based on the classification data available in the TCGA cohort description (IHC and PAM50 classification). Fourteen cases have a mutation in BRCA1: 10 TNBC, 3 luminal A BC, 1 HER2+ BC (Table S5 in Additional file 4).

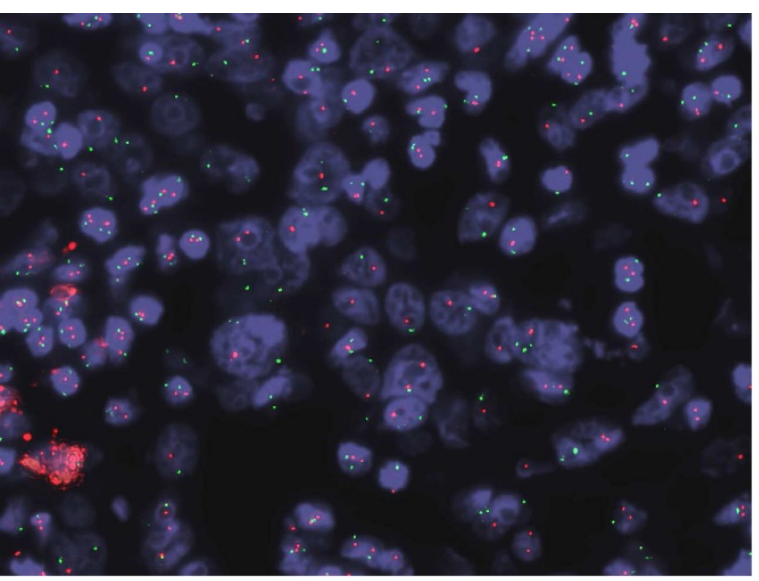

BRCA1-non-mutated TNBC

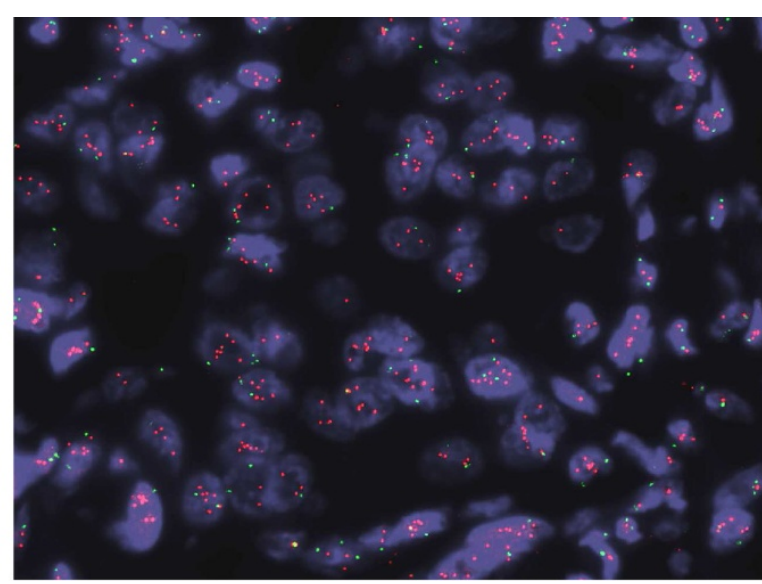

BRCA1-mutated TNBC

Figure 3 Fluorescent in situ hybridization analysis of the 17q25.3 chromosomal region in BRCA1-mutated and non-mutated triple-negative breast cancer (TNBC). Samples were hybridized with a chromosome 17 centromeric probe (green) and the 17q25.3-specific BAC probe (RP11-1055B8) (red). Copy number gain in the 17q25.3 region is clearly visible in this representative mutated case. 
Table 3 Quantification of 17q25.3 gain in BRCA1-mutated and non-mutated TNBC by FISH

\begin{tabular}{|c|c|c|c|c|c|c|c|c|c|}
\hline \multirow[t]{4}{*}{ BRCA1 } & \multirow{4}{*}{ Number } & \multirow{2}{*}{\multicolumn{2}{|c|}{$\begin{array}{l}\text { aCGH } \\
\text { Gain in } 17 q 25.3\end{array}$}} & \multirow{2}{*}{\multicolumn{2}{|c|}{$\begin{array}{l}\text { FISH: mean number of 17qter copies } \\
\text { Median (IQR) }\end{array}$}} & \multirow{4}{*}{$\begin{array}{l}\text { Mann-Whitney } \\
\text { test } \\
P \text {-value }\end{array}$} & \multicolumn{2}{|c|}{ FISH: \% cells with ratio >3 } & \multirow{4}{*}{$\begin{array}{l}\text { Mann-Whitney } \\
\text { test } \\
P \text {-value }\end{array}$} \\
\hline & & & & & & & \multicolumn{2}{|l|}{ Median (IQR) } & \\
\hline & & + & - & $\mathrm{aCGH}$ & $\mathrm{aCGH}$ & & $\mathrm{aCGH}$ & aCGH & \\
\hline & & & & Gain in $17 q 25.3$ & No gain in $17 q 25.3$ & & Gain in $17 q 25.3$ & No gain in $17 q 25.3$ & \\
\hline$\overline{\text { All }}$ & 44 & 26 & 18 & 3.6 (2.9 to 4.2$)$ & 2.1 (1.7 to 2.6 ) & 0.0001 & 20.6 (11.5 to 35.4$)$ & 0 (0 to 3.8) & 0.0001 \\
\hline Mutated & 23 & 20 & 3 & 3.5 (2.7 to 4.2 ) & 1.8 (1.8 to 2.7 ) & 0.0199 & 20.6 (9.9 to 34.2$)$ & $0(0$ to 10.6$)$ & 0.0253 \\
\hline Non-mutated & 21 & 6 & 15 & 3.6 (2.9 to 4.6$)$ & 2.1 (1.7 to 2.6$)$ & 0.0009 & 24.0 (14.1 to 33.9) & $0(0$ to 3.5$)$ & 0.0007 \\
\hline
\end{tabular}

TNBC, triple-negative breast cancer; aCGH, array comparative genomic hybridization. 


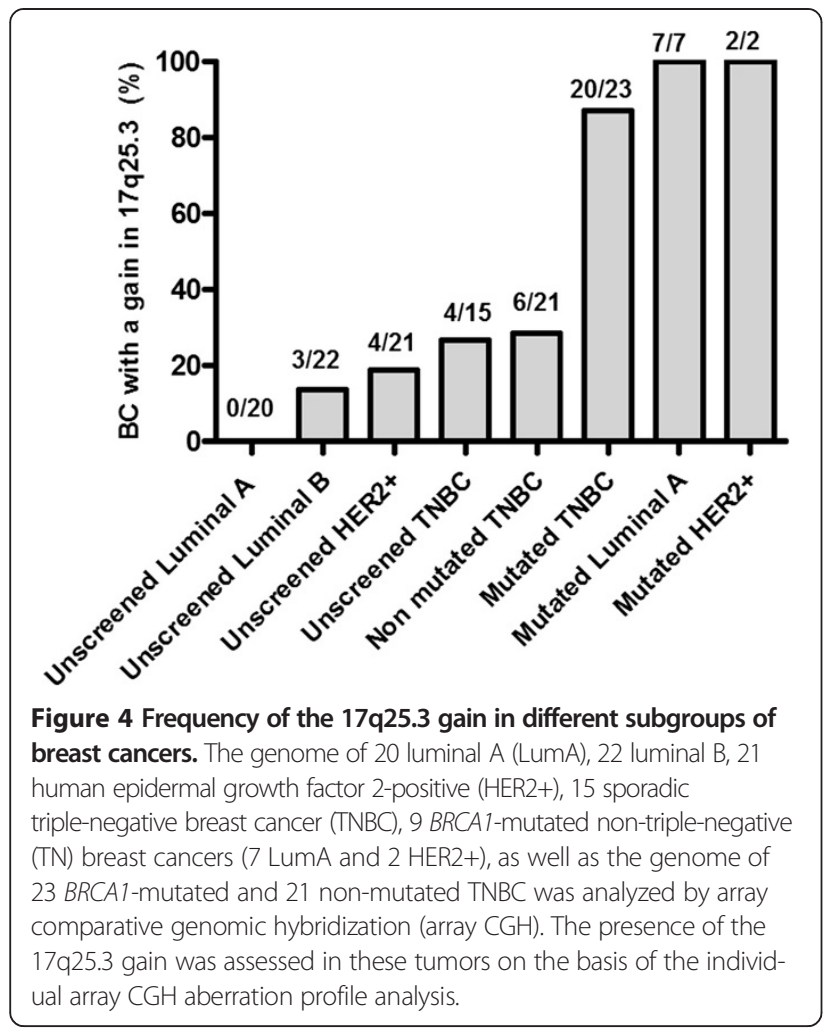

A gain in $17 \mathrm{q} 25.3$ was detected in $70 \%(7 / 10)$ of the $B R C A 1$-mutated TNBC and in one of the mutated luminal A BC. No gain was detected in the mutated HER2+ BC, but the mutation in that sample is classified as low impact (p.D1344H) and might have no impact on the protein function. The gain was detected in $30 \%(20 / 67)$ of the TNBC without identified BRCA1 mutation, in $36 \%(14 / 38)$ of the HER2+ BC cases, in 17\% (35/201) of the luminal A cases and in $43 \%(43 / 101)$ of the luminal B cases. Thus, in the TCGA cohort, the gain in 17q25.3 was also more frequent in the $B R C A 1$-mutated samples compared to $\mathrm{BC}$ without identified $B R C A 1$ mutation.
Interestingly, 26\% (9 of the 35) of the LumA, 23\% (10/43) of the LumB, 28\% (4/14) of HER2+ and 45\% (9/20) of the non-mutated TN with a 17q25.3 gain have a mutation, homozygous deletion or diminished expression in other genes involved in DNA repair (ATM, BRCA2, CHECK2, FANCF, MLH1, et cetera).

\section{Gene expression analysis of the 17q25.3 chromosomal region in BRCA1-mutated and non-mutated TNBC}

Several studies have shown that genome amplification can lead to the over-expression of genes located in the amplified regions (amplicon). This over-expression may contribute to tumor development and progression. According to our $\mathrm{CGH}$ analyses, the $17 \mathrm{q} 25.3$ subregion of interest spreads from the position 78644018 to 81029941 (NCBI built 37) and contains 65 protein coding genes. We investigated by low-density Taqman array the expression of the 65 genes of the $17 \mathrm{q} 25.3$ region in BRCA1-mutated and non-mutated TNBC previously analyzed by array CGH. Relative expression levels were compared to identify significant differently expressed genes in mutated tumors. Expression data analysis identified a significant over expression of 17 genes (ARHGDIA, AZI1, C17orf56, C17orf62, CSNK1D, DUS1L, FLJ9 0757, FN3KRP, GPS1, HGS, NPLOC4, RFNG, RPTOR, SIRT7, SCL25A10, SCL38A10, THOC4) in BRCA1-mutated TNBC (and CGH-positive for the gain in the 17q25.3 region) as compared to the non-mutated TNBC (and CGHnegative for the 17q25.3 region). Relative expression levels of these genes are presented in Figure 5 and in Additional file 4: Table S6).

In order to validate the expression levels measured with the Taqman low-density arrays, individual Taqman assays were performed on 15 BRCA1-mutated and 13 nonmutated TNBC. In this validation step, the relative expression of 8 out of the 17 genes was assessed (C17orf56, CSNK1D, DUS1L, FN3KRP, HGS, SIRT7, SCL25A10, $R F N G$ ). The results of this validation, presented in Figure 6 and Additional file 4: Table S7, confirm the over expression detected by Taqman low density arrays in BRCA1-

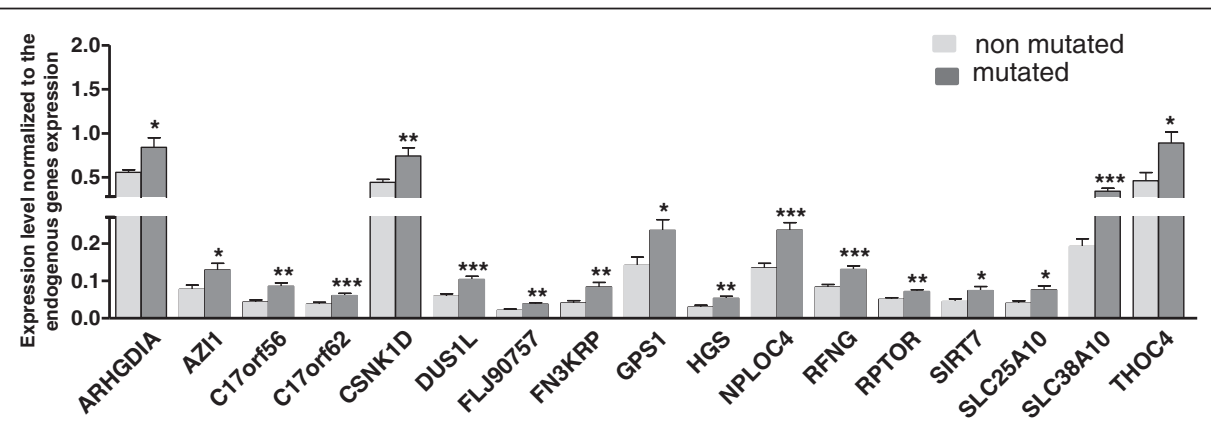

Figure 5 Genes of the 17q25.3 chromosomal region differentially expressed between BRCA1-mutated $(n=15)$ and non-mutated triple-negative breast cancer (TNBC) $(n=13)$. The analysis was carried out using customized Taqman low-density arrays. Statistical analysis: two-tailed Student's $t$-test: ${ }^{*} P<0.05 ;{ }^{*} P<0.01 ; * * * P<0.001$. 


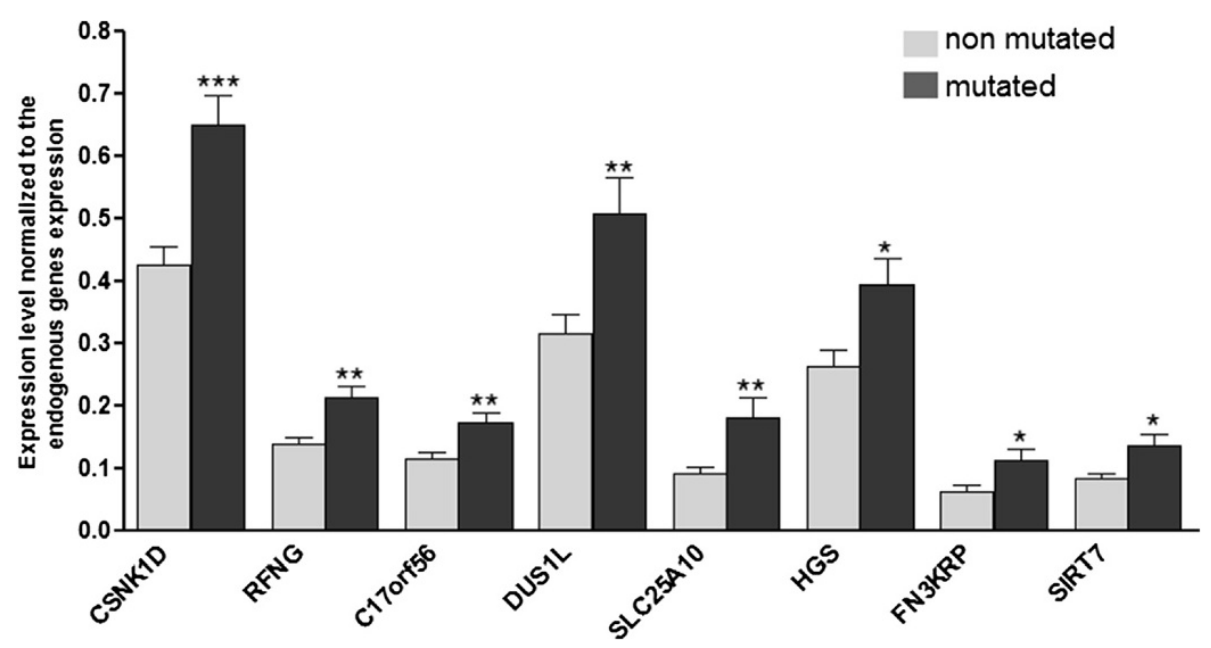

Figure 6 Validation of Taqman low-density array analysis (TLDA) gene expression level. The expression of eight genes previously studied by TLDA (CSNK1D, RFNG, C17orf56, DUS1L, SLC25A10, HGS, FN3KRP, SIRT7) was assessed in 15 BRCA1-mutated and 13 non-mutated triple-negative breast cancer (TNBC) using a standard qPCR method. Statistical analysis: two-tailed Student's $t$-test: ${ }^{*} P<0.05$; ${ }^{* *} P<0.01$; ${ }^{* * *} P<0.001$.

mutated TNBC with a gain in 17q25.3. Compared to the non-mutated cases, expression levels are increased up to two times in the BRCA1-mutated group. As the RNA extracted from the tumor is probably contaminated by RNA extracted from normal cells, with TNBC often deeply infiltrated by numerous stromal and inflammatory diploid cells, the over expression in the tumor cells could be more important than what we have observed.

To validate our experimental results, the expression of several genes of the 17q25.3 region (ARHGDIA, AZI1, C17orf56, DUS1L, FN3KRP, HGS, SIRT7, SCL25A10) was compared in TNBC with or without a gain in the TCGA study (Z-scores values retrieved from [23]). In agreement with our own observations, tumors with copy number gains have an increased gene expression compared to cases without the 17q25.3 gain (Figure S2 in Additional file 4).

To gain insight into the importance of the genes in the $17 q 25.3$ region, we analyzed publically available shRNA screen databases (COLT-cancer and genomeRNAi, Table S8 and S9 in Additional file 4) [24,25]. In COLT-cancer, 9 of the 16 genes analyzed in our study (AZI1, CSNK1D, DUS1L, FN3KRP, GPS1, RFNG, RPTOR, THOC4 and $H G S$ ) were found to be essential for survival in at least one cancer cell line. Some genes, like THOC4, are essential in almost all the cell lines tested. Interestingly, several of the genes in the 17q25.3 region were identified in shRNA screenings for genes involved in maintenance of genome stability or response to DNA damage (ARGHDIA, GPS1, SLC38A10, THOC4) [26-30].

\section{Methylation status of the BRCA1 gene promoter in 17q25.3-amplified TNBC}

The gain in the $17 q 25.3$ region is highly recurrent in the BRCA1-mutated TNBC. However, this gain was also detected in non-mutated or unscreened samples. Epigenetic inactivation of tumor suppressor genes is a wellknown mechanism. Methylation of the BRCA1 promoter has been reported in about 10 to $30 \%$ of breast cancers [31-33] and BRCA1-methylated tumors have a BRCA1like phenotype [34]. The presence of the $17 \mathrm{q} 25.3$ gain in the non-mutated TNBC could possibly be explained by this mechanism and hypermethylation of $B R C A 1$ promoter was assessed in the $\mathrm{BC}$ analyzed by array $\mathrm{CGH}$.

Interestingly, $B R C A 1$ promoter methylation was not detected in the TNBC $(\mathrm{n}=21)$ and non-TNBC $(\mathrm{n}=9)$ carrying a $B R C A 1$ germline mutation. In the non-mutated TNBC, $B R C A 1$ promoter methylation was detected in seven TNBC (33\%). Amongst these seven cases, four displayed a BRCA1like profile, with a gain in $17 \mathrm{q} 25.3$. In the unscreened TNBC, BRCA1 promoter methylation was observed in three tumors $(20 \%)$ and the gain in $17 \mathrm{q} 25.3$ was detected in one TNBC (Figure 7). Altogether, the gain was detected in $50 \%(5 / 10)$ of the TNBC with BRCA1 promoter methylation.

We did not detect $B R C A 1$ promoter methylation in the LumA, Lum B and HER2+ BC. To confirm our results, BRCA1 promoter methylation data (HM27 beta value data, available for 311 samples) were retrieved for the TCGA study (samples with HM27 beta value $>0.5$ and BRCA1 expression downregulation were considered as methylated). Methylation of the BRCA1 promoter was not detected in the 14 BRCA1 mutated samples from the TCGA study, but was detected in $16 \%$ of the TNBC without BRCA1 mutation (5/31 samples), in $0 \%$ of LumA (0/101) samples, in only $5 \%$ of LumB (3/64) samples and in 0\% of HER2+ (0/31) samples (Figure S3 in Additional file 4). Amongst the sample with BRCA1 promoter methylation, $50 \%(4 / 8)$ have a gain in $17 q 25.3$, a result similar to our own observations. 


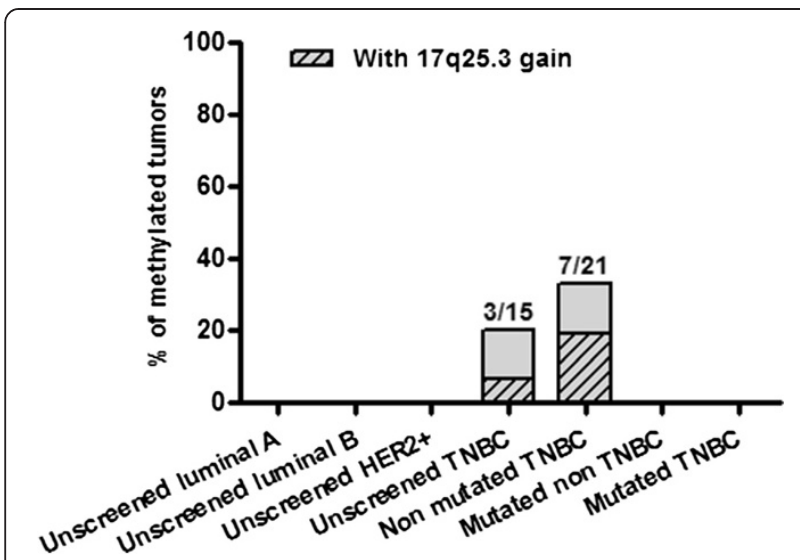

Figure 7 BRCA1 promotor methylation in breast cancer (BC). $B R C A 1$ promoter methylation was analyzed in 20 luminal $A, 22$ luminal $B, 21$ HER2+, 15 unscreened TN, 21 non-mutated TN, 23 BRCA1-mutated triple-negative (TN) and 9 mutated non-TN BC. Methylation of the BRCA1 promoter was only detected in the unscreened $(3 / 15,20 \%)$ or non-mutated $(7 / 21,33 \%)$ TNBC.

\section{Discussion}

We report the genomic profiles for BRCA1-mutated, nonmutated and unscreened TN breast tumors using DNA arrays composed of 60,000 probes with an average resolution of $40 \mathrm{~kb}$. Some of the aberrations reported in this study have been described before, and confirm findings from other studies using techniques with lower resolution, including losses in 5q11-23 and 12q21 and gains in 8q24 that were previously shown to be associated with BRCA1 tumors $[15,17,18,35]$.

We also describe the presence in BRCA1-mutated $\mathrm{BC}$ of a new recurrent and highly significant gain in the q25.3 region of chromosome 17. This 17q25.3 gain was detected in $90 \%$ of the BRCA1-mutated BC ( $86 \%$ of the mutated TNBC and $100 \%$ of the mutated non-TNBC) in our cohort and was also highly recurrent in the BRCA1-mutated breast cancer of the TCGA cohort. The gain was also present in $50 \%$ of the TNBC with $B R C A 1$ promoter methylation (TNBC unscreened for germline mutation or non-mutated TNBC).

Interestingly, in our study, BRCA1 epigenetic silencing and $B R C A 1$ mutation are mutually exclusive events, as $B R C A 1$ promoter methylation was never detected in BRCA1-mutated TNBC and was detected in $33 \%$ of the non-mutated TNBC. Our observations confirm similar results reported in previous studies in ovarian and breast cancer [33,36-38].

Amplification of the 17qter region has been described in several other cancer types, like prostate or ovarian cancers. A highly recurrent gain on chromosome $17 \mathrm{q} 25.3$ was reported in prostate cancer [39]. The region identified overlaps with the same region on chromosome 17q identified in our CGH assay. The significance of the presence of the 17q25.3 amplification in prostate cancer in relation to BRCA1 deficiency is not clear. In hereditary ovarian carcinoma,
Zweemer et al. have observed an amplification of the 17q24-25 region in 19\% of the cases (BRCA1- or BRCA2mutated and familial but non-mutated) [40]. Leunen et al. also reported a gain in 17q25 in BRCA1-mutated ovarian tumors [41]. However, to our knowledge, the 17q25.3 gain has never before been associated with BRCA1 mutation in breast cancer. The gain in $17 \mathrm{q} 25.3$ is highly recurrent in BRCA1 deficient TNBC, but was also detected in two nonmutated and unmethylated TNBC, and in two unscreened and unmethylated TNBC, in three LumB and in four HER2 $+\mathrm{BC}$.

We cannot exclude a BRCA1 mutation in the unscreened $\mathrm{BC}$, but this is very unlikely considering the rarity of the $B R C A 1$ mutation in luminal and HER2+ BC. For ethical reasons, it has not been possible to sequence BRCA1 in these samples. Several other mechanisms could be responsible for BRCA1 downregulation or BRCA1 pathway dysfunction in the TNBC samples. One such mechanism could be the action of the DNA binding protein ID4. This protein is highly expressed in TNBC and it has been shown that ID4 can block BRCA1 gene transcription in vitro and possibly downregulate $B R C A 1$ expression in vivo [42]. In the HER2+ BC, Chr17 usually displays very complex rearrangements [43]. This could be responsible for the $17 \mathrm{q} 25.3$ gain detected by CGH in these HER2+ amplified tumors.

In our work, some differences were observed in comparison to the CGH profiles that are available in the literature $[13,15,17,18,35,44]$. Such differences may arise from bias in patient selection. One of the major caveats of such studies is the heterogeneity of the tumor groups analyzed. Indeed, BRCA1-mutated breast cancers, which are mainly TN tumors, are often compared to non-mutated tumors, is the majority of which are not TNBC, but luminal A, luminal B or HER2+ tumors. Similarly, some studies involved BLBC, which constitute a heterogeneous group of tumors composed of about $75 \%$ TNBC and $25 \%$ non-TNBC (luminal A, luminal B, HER2+ BC) $[11,45]$. In this study, we have compared the genomic alterations linked to a defect in BRCA1 within one breast cancer subtype, the TNBC. Another important methodological difference that must be considered is the type of CGH arrays used to perform the analyses. Most of the studies used BAC arrays that typically scan the genome at $1-$ or $2-\mathrm{Mb}$ resolution, which can be considered low. The array CGH used in our study allow genome coverage at a mean resolution of about $40 \mathrm{~kb}$. A better coverage of the genome allows for the identification of more numerous and smaller aberrations that cannot be detected with analytical tools of lower resolution. The coverage of the genome can also be different. For example, the BAC arrays used in the work of Joosse do not cover the specific subregion of the $17 \mathrm{q} 25.3$ cytoband that we detected in our study [17]. The homogeneity of the tumor groups as well as the $60 \mathrm{k} \mathrm{CGH}$ arrays used in our study could explain, at least in part, the fact that we 
were able to detect the $17 \mathrm{q} 25.3$ amplification in BRCA1-mutated tumors that was not found in the other studies.

It has been shown that genes that are consistently overexpressed when amplified may be required for the survival of cancer cells and may also have the potential to be therapeutic targets [46-48]. We validated eight genes of the 17q25.3 region that were significantly over-expressed in tumors harboring the 17q25.3 gain compared to negative tumors (C17orf56, CSNK1D, DUS1L, FN3KRP, HGS, SIRT7, $S C L 25 A 10, R F N G)$. Some of these over-expressed genes in the $17 \mathrm{q} 25.3$ region have been linked to cancer development and progression. The Casein kinase 1 delta (CSNK1D) has been implicated in colon, pancreatic and breast cancer and reduced CSNK1D activity impairs mammary tumorigenesis in vivo [49,50]. HGS, the hepatocyte growth factorregulated tyrosine kinase substrate, has been implicated in tumor growth and metastasis and over-expression of HGS prevents the degradation of the EGF receptor [51,52].

It has recently been demonstrated that SIRT7 is a selective H3K18Ac deacetylase that mediates transcriptional repression and stabilizes the cancer cell phenotype [53]. Deletion of SIRT7 in a xenograft model inhibits the growth of human cancer cells. In this context, it is tempting to make a link between the over-expression of SIRT7 and the sensitivity of some TNBC to deacetylase inhibitor [54].

Some of the genes of the 17q25.3 region have been linked to DNA repair in shRNA screens and their overexpression might affect the DNA repair capacity of the cell. Hence, upregulation of the DNA repair capacity of the cancer cell might represent a mechanism used to overcome the lack of a BRCA1-dependent repair mechanism.

Further studies will be carried out to address the functional significance and clinical relevance of the 17q25.3 gain and gene over-expression in BRCA1-mutated breast cancer, such as the prediction of the response to alkylating agent or platinum-based therapy.

\section{Conclusions}

In this project, we have established an array CGH profile of BRCA1 mutant TNBC. Particularly, we have identified a gain in the $17 \mathrm{q} 25.3$ region that is highly recurrent in BRCA1-mutated breast cancer. Several genes of this region are upregulated and might represent potential therapeutic targets.

\section{Additional files}

Additional file 1: Table S1. Chromosomal aberrations detected in BRCA1 mutated and non-mutated triple-negative breast cancer (TNBC) by array comparative genomic hybridization $(\mathrm{CGH})$.
Additional file 2: Table S2. Gains and losses detected in BRCA1 non-mutated triple-negative breast cancer (TNBC) by array comparative genomic hybridization (CGH).

Additional file 3: Table S3. List of the 145 most important segments. Additional file 4: Supplementary methods and results. Table S4. classification results. Table S5. list of samples from the triple-negative breast cancer (TCGA) breast cancer used in this study. Table S6. Relative gene expression in mutated and non-mutated TNBC (Taqman low density arrays). Table S7. Relative gene expression in mutated and non-mutated TNBC (Taqman qPCR). Table S8 COLT-cancer database analysis. Table S8. GenomeRNAI database analysis. Figures S1 to S3.

\section{Abbreviations}

Array CGH: array comparative genomic hybridization; BAC: bacterial artificial chromosome; BC: breast cancer; BLBC: basal-like breast cancer; BRCA1: Breast cancer 1 gene; BRCA2: Breast cancer 2 gene; CK 14: cytokeratin 14; CK5/ 6: cytokeratin 5/6; Ct: cycle threshold; EGFR: epidermal growth factor receptor; ER: estrogen receptor; FFPE: formalin-fixed paraffin-embedded; FISH: fluorescent in situ hybridization; HE: hematoxylin and eosin stain; HER2: human epidermal growth factor receptor 2;

IHC: immunohistochemical; PARP: poly ADP ribose polymerase; PR: progesterone receptor; TMA: tissue microarray; TNBC: triple negative breast cancer.

\section{Competing interests}

Fabrice Moreau and Wim Van Criekinge were employees of MDxHealth. All the other authors declare that they have no conflict of interest.

\section{Authors' contributions}

ST conceived and designed the study, carried out the array and the expression experiments, participated in the collection, assembly, analysis and interpretation of data and drafted the manuscript. IB conceived and designed the study, carried out the FISH experiments, participated in the collection, assembly, analysis and interpretation of data and drafted the manuscript. FA participated in the assembly, analysis and interpretation of data and revised the manuscript. PH participated in the collection, assembly, analysis and interpretation of data. FC participated in the collection and assembly of data. FM and WVC performed the methylation analysis. MC, ALM and HR analysed the data and interpreted the results. MLT, JPM and JC conceived the study, analysed the data, interpreted the results and reviewed the manuscript. PD and JLC conceived and designed the study, participated in the collection, assembly, analysis and interpretation of data and reviewed the manuscript. All authors read and approved the final manuscript.

\section{Acknowledgements}

This work was financed through the Plan National Cancer - Action 29 (Belgium) and supported by the PACS08 study (UNICANCER, France). Jean-Baptiste Poullet (Stat'Rgy, Naninne, Belgium) built the SVM model. We thank Aline Van Maanen and Loic Campione for help with statistical analysis. We thank Dr François Duhoux for critically reviewing the manuscript.

\section{Author details}

'Laboratory of Translational Oncology, Institute of Pathology and Genetics/ Grand Hôpital de Charleroi, Avenue Georges Lemaître 25, Gosselies 6041, Belgium. ${ }^{2}$ Tumor Bank, Institute of Pathology and Genetics, Avenue Georges Lemaître 25, Gosselies 6041, Belgium. ${ }^{3}$ Department of Pathology, Institute of Pathology and Genetics, Avenue Georges Lemaitre 25, Gosselies 6041, Belgium. ${ }^{4}$ Department of Molecular Biology, Institute of Pathology and Genetics, Avenue Georges Lemaître 25, Gosselies 6041, Belgium. ${ }^{5}$ MdxHealth Inc 15279 Alton Parkway, Suite 100, Irvine, CA 92618, USA. ${ }^{6}$ Département de Biologie et de Pathologie, Institut Claudius Regaud, 20-24, Rue Pont St Pierre, Toulouse 31052, France. ${ }^{7}$ Département d'Oncologie Médicale, Institut de Cancérologie de l'Ouest-René Gauducheau, Boulevard Jacques Monod, Saint-Herblain, Nantes 44805, France. ${ }^{8}$ R\&D UNICANCER, UNICANCER, Rue de Tolbiac 101, Paris Cedex 13 75654, France. ${ }^{9}$ Département d'Oncologie Médicale, Institut Claudius Regaud, 20-24, Rue Pont St Pierre, Toulouse 31300, France. ${ }^{10}$ Department of Oncology, Cliniques Universitaires Saint-Luc, Avenue Hippocrate 10, Brussels 1200, Belgium. ${ }^{11}$ Service of Oncology-Hematology, Grand Hôpital de Charleroi, Grand'Rue, 3, Charleroi 6000, Belgium. 
Received: 27 January 2014 Accepted: 17 October 2014

Published online: 22 November 2014

\section{References}

1. Perou CM, Sorlie T, Eisen MB, van de Rijn M, Jeffrey SS, Rees CA, Pollack JR, Ross DT, Johnsen H, Akslen LA, Fluge O, Pergamenschikov A, Williams C, Zhu SX, Lonning PE, Borresen-Dale AL, Brown PO, Botstein D: Molecular portraits of human breast tumours. Nature 2000, 406:747-752.

2. Sorlie T, Perou CM, Tibshirani R, Aas T, Geisler S, Johnsen H, Hastie T, Eisen MB, van de Rijn M, Jeffrey SS, Thorsen T, Quist H, Matese JC, Brown PO, Botstein D, Eystein Lonning P, Borresen-Dale AL: Gene expression patterns of breast carcinomas distinguish tumor subclasses with clinical implications. Proc Natl Acad Sci USA 2001, 98:10869-10874.

3. Sotiriou C, Wirapati P, Loi S, Harris A, Fox S, Smeds J, Nordgren H, Farmer P, Praz V, Haibe-Kains B, Desmedt C, Larsimont D, Cardoso F, Peterse H, Nuyten D, Buyse M, Van de Vijver MJ, Bergh J, Piccart M, Delorenzi M: Gene expression profiling in breast cancer: understanding the molecular basis of histologic grade to improve prognosis. J Natl Cancer Inst 2006, 98:262-272.

4. Nielsen TO, Hsu FD, Jensen K, Cheang M, Karaca G, Hu Z, Hernandez-Boussard T, Livasy C, Cowan D, Dressler L, Akslen LA, Ragaz J, Gown AM, Gilks CB, van de Rijn $M$, Perou CM: Immunohistochemical and clinical characterization of the basal-like subtype of invasive breast carcinoma. Clin Cancer Res 2004, 10:5367-5374.

5. Cheang MCU, Voduc D, Bajdik C, Leung S, McKinney S, Chia SK, Perou CM, Nielsen TO: Basal-like breast cancer defined by five biomarkers has superior prognostic value than triple-negative phenotype. Clin Cancer Res 2008, 14:1368-1376.

6. Bosch A, Eroles P, Zaragoza R, Viña JR, Lluch A: Triple-negative breast cancer: molecular features, pathogenesis, treatment and current lines of research. Cancer Treat Rev 2010, 36:206-215.

7. Gluz O, Liedtke C, Gottschalk N, Pusztai L, Nitz U, Harbeck N: Triple-negative breast cancer-current status and future directions. Ann Oncol 2009, 20:1913-1927.

8. Evans DG, Howell A, Ward D, Lalloo F, Jones JL, Eccles DM: Prevalence of BRCA1 and BRCA2 mutations in triple negative breast cancer. J Med Genet 2011, 48:520-522.

9. Robertson L, Hanson H, Seal S, Warren-Perry M, Hughes D, Howell I, Turnbull C, Houlston R, Shanley S, Butler S, Evans DG, Ross G, Eccles D, Tutt A, Rahman N: BRCA1 testing should be offered to individuals with triple-negative breast cancer diagnosed below 50 years. Br J Cancer 2012, 106:1234-1238.

10. Turner N, Tutt A, Ashworth A: Hallmarks of 'BRCAness' in sporadic cancers. Nat Rev Cancer 2004, 4:814-819.

11. Lehmann B, Bauer J, Chen X, Sanders M, Chakravarthy A, Shyr Y, Pietenpol J: Identification of human triple-negative breast cancer subtypes and preclinical models for selection of targeted therapies. J Clin Invest 2011, 121:2750-2767.

12. Silver DP, Richardson AL, Eklund AC, Wang ZC, Szallasi Z, Li Q, Juul N, Leong CO, Calogrias D, Buraimoh A, Fatima A, Gelman RS, Ryan PD, Tung NM, De Nicolo A, Ganesan S, Miron A, Colin C, Sgroi DC, Ellisen LW, Winer EP, Garber JE: Efficacy of neoadjuvant Cisplatin in triple-negative breast cancer. J Clin Oncol 2010, 28:1145-1153.

13. Vollebergh MA, Lips EH, Nederlof PM, Wessels LFA, Schmidt MK, van Beers EH, Cornelissen S, Holtkamp M, Froklage FE, de Vries EGE, Schrama JG, Wesseling J, van de Vijver MJ, van Tinteren H, de Bruin M, Hauptmann M, Rodenhuis S, Linn SC: An aCGH classifier derived from BRCA1-mutated breast cancer and benefit of high-dose platinum-based chemotherapy in HER2-negative breast cancer patients. Ann Oncol 2011, 22:1561-1570.

14. Anders CK, Winer EP, Ford JM, Dent R, Silver DP, Sledge GW, Carey LA: Poly (ADP-Ribose) polymerase inhibition: "targeted" therapy for triplenegative breast cancer. Clin Cancer Res 2010, 16:4702-4710.

15. Stefansson OA: Genomic profiling of breast tumours in relation to BRCA abnormalities and phenotypes. Breast Cancer Res 2009, 11:R47.

16. Joosse SA, Brandwijk KI, Mulder L, Wesseling J, Hannemann J, Nederlof PM: Genomic signature of BRCA1 deficiency in sporadic basal-like breast tumors. Gene Chromosome Cancer 2011, 50:71-81.

17. Joosse SA, van Beers EH, Tielen $I H$, Horlings $H$, Peterse $J$, Hoogerbrugge $N$, Ligtenberg MJ, Wessels LF, Axwijk P, Verhoef S, Hogervorst FB, Nederlof PM: Prediction of BRCA1-association in hereditary non-BRCA1/2 breast carcinomas with array-CGH. Breast Cancer Res Treat 2009, 116:479-489.

18. Jönsson G, Naylor TL, Vallon-Christersson J, Staaf J, Huang J, Ward MR, Greshock JD, Luts L, Olsson H, Rahman N, Stratton M, Ringnér M, Borg Å, Weber BL: Distinct genomic profiles in hereditary breast tumors identified by array-based comparative genomic hybridization. Cancer Res 2005, 65:7612-7621.
19. MacDonald JR, Ziman R, Yuen RKC, Feuk L, Scherer SW: The Database of Genomic Variants: a curated collection of structural variation in the human genome. Nucleic Acids Res 2014, 42:D986-D992.

20. Herman JG, Graff JR, Myohanen S, Nelkin BD, Baylin SB: Methylation-specific PCR a novel PCR assay for methylation status of CpG islands. Proc Natl Acad Sci USA 1996, 93:9821-9826.

21. Veeck J, Ropero S, Setien F, Gonzalez-Suarez E, Osorio A, Benitez J, Herman JG, Esteller M: BRCA1 CpG island hypermethylation predicts sensitivity to poly(adenosine diphosphate)-ribose polymerase inhibitors. J Clin Oncol 2010, 28:e563-e564. author reply e565-566.

22. The Cancer Genome Atlas Network: Comprehensive molecular portraits of human breast tumours. Nature 2012, 490:61-70.

23. Cerami E, Gao J, Dogrusoz U, Gross BE, Sumer SO, Aksoy BA, Jacobsen A, Byrne CJ, Heuer ML, Larsson E, Antipin Y, Reva B, Goldberg AP, Sander C, Schultz N: The cBio Cancer Genomics Portal: an open platform for exploring multidimensional cancer genomics data. Cancer Discov 2012, 2:401-404.

24. Koh JLY, Brown KR, Sayad A, Kasimer D, Ketela T, Moffat J: COLT-Cancer: functional genetic screening resource for essential genes in human cancer cell lines. Nucleic Acids Res 2012, 40:D957-D963.

25. Schmidt EE, Pelz O, Buhlmann S, Kerr G, Horn T, Boutros M: GenomeRNAi: a database for cell-based and in vivo RNAi phenotypes, 2013 update. Nucleic Acids Res 2013, 41:D1021-D1026.

26. Paulsen RD, Soni DV, Wollman R, Hahn AT, Yee M-C, Guan A, Hesley JA, Miller SC, Cromwell EF, Solow-Cordero DE, Meyer T, Cimprich KA: A Genome-wide siRNA Screen Reveals Diverse Cellular Processes and Pathways that Mediate Genome Stability. Mol Cell 2009, 35:228-239.

27. Hurov KE, Cotta-Ramusino C, Elledge SJ: A genetic screen identifies the Triple T complex required for DNA damage signaling and ATM and ATR stability. Genes Dev 2010, 24:1939-1950.

28. Słabicki M, Theis M, Krastev DB, Samsonov S, Mundwiller E, Junqueira M, Paszkowski-Rogacz M, Teyra J, Heninger A-K, Poser I, Prieur F, Truchetto J, Confavreux C, Marelli C, Durr A, Camdessanche JP, Brice A, Shevchenko A, Pisabarro MT, Stevanin G, Buchholz F: A genome-scale DNA repair RNAi screen identifies SPG48 as a novel gene associated with hereditary spastic paraplegia. PLoS Biol 2010, 8:e1000408.

29. Takazawa K. Tsuchiya H, Yoshimichi U, Kanazawa Y, li S, Tomita K: Expression analysis for the identification of genes involved in acquired resistance to cisplatin in osteosarcoma cells. Cancer Genomics Proteomics 2006, 3:373-381.

30. Matsuoka S, Ballif BA, Smogorzewska A, McDonald ER, Hurov KE, Luo J, Bakalarski CE, Zhao Z, Solimini N, Lerenthal Y, Shiloh Y, Gygi SP, Elledge SJ: ATM and ATR substrate analysis reveals extensive protein networks responsive to DNA damage. Science 2007, 316:1160-1166.

31. Rice JC, Ozcelik H, Maxeiner P, Andrulis I, Futscher BW: Methylation of the BRCA1 promoter is associated with decreased BRCA1 mRNA levels in clinical breast cancer specimens. Carcinogenesis 2000, 21:1761-1765.

32. Wei M, Grushko TA, Dignam J, Hagos F, Nanda R, Sveen L, Xu J, Fackenthal J, Tretiakova M, Das S, Olopade Ol: BRCA1 promoter methylation in sporadic breast cancer is associated with reduced BRCA1 copy number and chromosome 17 aneusomy. Cancer Res 2005, 65:10692-10699.

33. Ali A, lau P, Sng J-H: Cancer-specific methylation in the BRCA1 promoter in sporadic breast tumours. Med Oncol 2011, 28:64-66.

34. Bal A, Verma S, Joshi K, Singla A, Thakur R, Arora S, Singh G: BRCA1-methylated sporadic breast cancers are BRCA-like in showing a basal phenotype and absence of ER expression. Virchows Arch 2012, 461:305-312.

35. Tirkkonen M, Johannsson O, Agnarsson BA, Olsson H, Ingvarsson S, Karhu R, Tanner M, Isola J, Barkardottir RB, Borg Å, Kallioniemi O-P: Distinct somatic genetic changes associated with tumor progression in carriers of BRCA1 and BRCA2 germ-line mutations. Cancer Res 1997, 57:1222-1227.

36. Lips EH, Mulder L, Oonk A, van der Kolk LE, Hogervorst FB, Imholz AL, Wesseling J, Rodenhuis S, Nederlof PM: Triple-negative breast cancer: BRCAness and concordance of clinical features with BRCA1-mutation carriers. Br J Cancer 2013, 108:2172-2177.

37. Bol GM, Suijkerbuijk KP, Bart J, Vooijs M, van der Wall E, van Diest PJ: Methylation profiles of hereditary and sporadic ovarian cancer. Histopathology 2010 57:363-370.

38. Cancer Genome Atlas Research N: Integrated genomic analyses of ovarian carcinoma. Nature 2011, 474:609-615.

39. Bermudo R, Abia D, Benitez D, Carrió A, Vilella R, Ortiz ÁR, Thomson TM, Fernández PL: Discovery of genomic alterations through coregulation analysis of closely linked genes: a frequent gain in $17 \mathrm{q} 25.3$ in prostate cancer. Ann NY Acad Sci 2010, 1210:17-24. 
40. Zweemer RP, Ryan A, Snijders AM, Hermsen MA, Meijer GA, Beller U, Menko $\mathrm{FH}$, Jacobs IJ, Baak JP, Verheijen RH, Kenemans P, van Diest PJ: Comparative genomic hybridization of microdissected familial ovarian carcinoma: two deleted regions on chromosome $15 q$ not previously identified in sporadic ovarian carcinoma. Lab Invest 2001, 81:1363-1370.

41. Leunen K, Gevaert O, Daemen A, Vanspauwen V, Michils G, De Moor B, Moerman P, Vergote I, Legius E: Recurrent copy number alterations in BRCA1-mutated ovarian tumors alter biological pathways. Hum Mutat 2009, 30:1693-1702.

42. Wen Y, Ho A, Patil S, Akram M, Catalano J, Eaton A, Norton L, Benezra R, Brogi E: Id4 protein is highly expressed in triple-negative breast carcinomas: possible implications for BRCA1 downregulation. Breast Cancer Res Treat 2012, 135:93-102.

43. Marchiò C, Lambros MB, Gugliotta P, Di Cantogno LV, Botta C, Pasini B, Tan DSP, Mackay A, Fenwick K, Tamber N, Bussolati G, Ashworth A, Reis-Filho JS, Sapino A: Does chromosome 17 centromere copy number predict polysomy in breast cancer? A fluorescence in situ hybridization and microarray-based CGH analysis. J Pathol 2009, 219:16-24.

44. Jonsson G, Staaf J, Vallon-Christersson J, Ringner M, Holm K, Hegardt C, Gunnarsson H, Fagerholm R, Strand C, Agnarsson BA, Kilpivaara O, Luts L, Heikkila P, Aittomaki K, Blomqvist C, Loman N, Malmstrom P, Olsson H, Johannsson OT, Arason A, Nevanlinna H, Barkardottir RB, Borg A: Genomic subtypes of breast cancer identified by array-comparative genomic hybridization display distinct molecular and clinical characteristics. Breast Cancer Res 2010, 12:R42

45. Prat A, Adamo B, Cheang MCU, Anders CK, Carey LA, Perou CM: Molecular characterization of basal-like and non-basal-like triple-negative breast cancer. Oncologist 2013, 18:123-133.

46. Abba MC, Sun H, Hawkins KA, Drake JA, Hu Y, Nunez Ml, Gaddis S, Shi T, Horvath S, Sahin A, Aldaz CM: Breast cancer molecular signatures as determined by SAGE: correlation with lymph node status. Mol Cancer Res 2007, 5:881-890.

47. Bernard-Pierrot I, Gruel N, Stransky N, Vincent-Salomon A, Reyal F, Raynal V, Vallot C, Pierron G, Radvanyi F, Delattre O: Characterization of the recurrent 8p11-12 amplicon identifies PPAPDC1B, a phosphatase protein, as a new therapeutic target in breast cancer. Cancer Res 2008, 68:7165-7175.

48. Natrajan R, Mackay A, Wilkerson P, Lambros M, Wetterskog D, Arnedos M, Shiu K-K, Geyer F, Langerod A, Kreike B, Reyal F, Horlings H, van de Vijver M, Palacios J, Weigelt B, Reis-Filho J: Functional characterization of the $19 q 12$ amplicon in grade III breast cancers. Breast Cancer Res 2012, 14:R53.

49. Brockschmidt C, Hirner H, Huber N, Eismann T, Hillenbrand A, Giamas G, Radunsky B, Ammerpohl O, Bohm B, Henne-Bruns D, Kalthoff H, Leithauser F, Trauzold A, Knippschild U: Anti-apoptotic and growth-stimulatory functions of CK1 delta and epsilon in ductal adenocarcinoma of the pancreas are inhibited by IC261 in vitro and in vivo. Gut 2008, 57:799-806.

50. Hirner H, Gunes C, Bischof J, Wolff S, Grothey A, Kuhl M, Oswald F, Wegwitz F, Bos MR, Trauzold A, Henne-Bruns D, Peifer C, Leithauser F, Deppert W, Knippschild U: Impaired CK1 delta activity attenuates SV40-induced cellular transformation in vitro and mouse mammary carcinogenesis in vivo. PLoS One 2012, 7:e29709.

51. Walter-Yohrling J, Cao X, Callahan M, Weber W, Morgenbesser S, Madden SL, Wang C, Teicher BA: Identification of genes expressed in malignant cells that promote invasion. Cancer Res 2003, 63:8939-8947.

52. Chin L-S, Raynor MC, Wei X, Chen H-Q, Li L: Hrs Interacts with Sorting Nexin 1 and Regulates Degradation of Epidermal Growth Factor Receptor. J Biol Chem 2001, 276:7069-7078.

53. Barber MF, Michishita-Kioi E, Xi Y, Tasselli L, Kioi M, Moqtaderi Z, Tennen RI, Paredes S, Young NL, Chen K, Struhl K, Garcia BA, Gozani O, Li W, Chua KF: SIRT7 links H3K18 deacetylation to maintenance of oncogenic transformation. Nature 2012, 487:114-118.

54. Tate CR, Rhodes LV, Segar HC, Driver JL, Pounder FN, Burow ME, Collins-Burow BM: Targeting triple-negative breast cancer cells with the histone deacetylase inhibitor panobinostat. Breast Cancer Res 2012, 14:R79.

doi:10.1186/s13058-014-0466-y

Cite this article as: Toffoli et al.: Identification by array comparative genomic hybridization of a new amplicon on chromosome $17 q$ highly recurrent in BRCA1 mutated triple negative breast cancer. Breast Cancer Research 2014 16:466.

\section{Submit your next manuscript to BioMed Central and take full advantage of:}

- Convenient online submission

- Thorough peer review

- No space constraints or color figure charges

- Immediate publication on acceptance

- Inclusion in PubMed, CAS, Scopus and Google Scholar

- Research which is freely available for redistribution 